\title{
IASSIST Call for Papers
}

This is first call for papers for the annual conference of the International Association for Social Science Information Services and Technology (IASSIST), being held in May 2005 in collaboration with the International Federation of Data Organisations (IFDO). Proposals for papers, sessions and poster/ demonstrations should be submitted by 10 th January 2005.

The IASSIST/IFDO Conference is being hosted in Edinburgh, Scotland UK over the period Wednesday 25th to Friday 27th May, 2005; this is preceded by workshops earlier in the week and followed by a Highland Weekend, for a less formal exchange of views. Details may be accessed via the IASSIST website at http://www.iassistdata.org, or directly at http://datalib.ed.ac. uk/iassist/

.IASSIST is an international organization of professionals working in and with information technology and data services to support research and teaching in the social sciences. Typical workplaces include data archives/libraries, statistical agencies, research centres, libraries, academic departments, government departments, and non-profit organizations, see the IASSIST website, above, for further information.

IFDO was established in 1977 in response to advanced research needs of the international social science community. The purpose of IFDO is to stimulate and coordinate worldwide data services and thus enhance social science research. For further information please visit http://www.ifdo. org/.

For over thirty years, IASSIST conferences have brought together data professionals, data producers, and data analysts from around the world. The Annual Conference, which itself moves about the world, and was last in Europe in 2001, is the forum for presentation of papers covering both new and persistent issues relating to access to data, documentation of data, and digital preservation, with special emphasis on the social sciences. The social sciences have a long history of data sharing activity which may make the conference of interest to colleagues in disciplines where open access practices to data have been on the policy agenda, with clear overlaps with digital curation, data publishing and e-science/ cyberinfrastructure initiatives.

The IASSIST Quarterly (IQ), available online from the IASSIST website and in print, is another important means of communication for the data community, and a suitable place for publication of papers presented at the Conference.

Of special note is the IASSIST Publication Award, intended to promote the Association's Five Year Strategic Plan, involving a cash prize for the winning paper. For further details see: http://www.iassistdata.org/publications/pubaward.html .

The theme for the 2005 Conference, Evidence and Enlightenment, highlights the need for empirical data in a society that wishes to know itself, and of the role that the IASSIST membership have in ensuring that researchers have continuing access to the data necessary for furthering scholarship and understanding. It also hints at intellectual activity during the latter half of the 18th century in Europe, and in Scotland in particular, which "would generate the basic attitudes and habits of mind that characterise the modern age" - Arthur Herman, The Age of Enlightenment, 2002. 


\section{IASSIST / IFDO 2005 Edinburg}

As IASSIST enters its fourth decade, the organization and the data community must confront a range of socio-economic and organisational challenges as well as technological opportunities. We seek submissions of papers, poster/demonstration sessions, and panel sessions on topics that address these issues, especially those that bear on:

\section{a.. data access \\ b.. data documentation \\ c.. data preservation}

d.. data use and current research activity.

Additional topics might also include data, information and statistical literacy, GIS and spatial data, and such as data publishing, annotation, provenance and authenticity in digital curation. For other key topics see previous IASSIST Conferences at http://www. iassistdata.org/conferences/index.html .

\section{Procedure}

The deadline for paper, session, and poster/ demonstration proposals is 10th January 2005. The Conference Program Committee will send notification of the acceptance of proposals on or before 10th February 2005.

Please send submissions, including proposed title and an abstract (recommended length 150 words) to: iassist05@ed.ac.uk.

Proposals for complete sessions, conventionally of a panel or of three/four papers within a 90 minute session, should contain information on the focus of the session, the organizer or moderator, and possible session participants. The session organizer or moderator will be responsible for the arranging and securing session participants.

Make plans to come to Edinburgh for the IASSIST/IFDO Conference in the week commencing 22nd May 2005 to help us make the 31 st IASSIST Conference "the best conference ever!' Further information on travel and accommodation is available at links from the IASSIST website . Online registration is scheduled to open on 17 January 2005. 